\title{
Addendum: Witschen, P.M., et al. Tumor Cell Associated Hyaluronan-CD44 Signaling Promotes Pro-Tumor Inflammation in Breast Cancer. Cancers 2020, 12, 1325
}

\author{
Patrice M. Witschen ${ }^{1}$, Thomas S. Chaffee ${ }^{2}$, Nicholas J. Brady ${ }^{3,+}+\mathbb{D}$, Danielle N. Huggins ${ }^{2}$, \\ Todd P. Knutson ${ }^{2,4}{ }^{\circledR}$, Rebecca S. LaRue ${ }^{2,4}$, Sarah A. Munro ${ }^{2,4}$, Lyubov Tiegs ${ }^{5}$, \\ James B. McCarthy 2,5 (D), Andrew C. Nelson 2,5,*(D) and Kathryn L. Schwertfeger 2,5,6,* \\ 1 Comparative and Molecular Biosciences Graduate Program, University of Minnesota, Minneapolis, \\ MN 55455, USA; witsc004@umn.edu \\ 2 Department of Laboratory Medicine and Pathology, University of Minnesota, Minneapolis, MN 55455, USA; \\ chaf0084@umn.edu (T.S.C.); drenner@umn.edu (D.N.H.); knut0297@umn.edu (T.P.K.); \\ larue005@umn.edu (R.S.L.); smunro@umn.edu (S.A.M.); mccar001@umn.edu (J.B.M.) \\ 3 Microbiology, Immunology and Cancer Biology Graduate Program, University of Minnesota, Minneapolis, \\ MN 55455, USA; njb2003@med.cornell.edu \\ 4 University of Minnesota Supercomputing Institute, University of Minnesota, Minneapolis, MN 55455, USA \\ 5 Masonic Cancer Center, University of Minnesota, Minneapolis, MN 55455, USA; gitts008@umn.edu \\ 6 Center for Immunology, University of Minnesota, Minneapolis, MN 55455, USA \\ * Correspondence: nels2055@umn.edu (A.C.N.); schwe251@umn.edu (K.L.S.) \\ + Present address: Department of Pathology and Laboratory Medicine, Weill Cornell Medicine, New York, \\ NY 10021, USA.
}

The authors wish to make the following corrections to this paper [1].

The authors would like to acknowledge Dr. Ali Khammanivong for providing gRNA sequences and guidance during the generation of the CD44 knockout cell lines. The authors would also like to acknowledge the Burroughs Wellcome Fund and the Howard Hughes Medical Institute Medical Research Fellowship program for providing funding for Dr. Witschen.

The original "Acknowledgments" is

Acknowledgments: The authors would like to thank Douglas Yee (funded by Masonic Cancer Center (MCC) Support Grant, P30-CA077598), and other members of the University of Minnesota Breast Cancer Translational Working Group (BrCa-TWG), for assistance with the cell line and patient Nanostring gene expression experiments. The authors would also like to thank the Elsa Pardee foundation (L.Furcht, Allen-Pardee Professor).

And should be replaced with:

Acknowledgments: The authors would like to thank Douglas Yee (funded by the Masonic Cancer Center (MCC) Support Grant, P30-CA077598), and other members of the University of Minnesota Breast Cancer Translational Working Group (BrCa-TWG), for assistance with the cell line and patient Nanostring gene expression experiments. The authors would also like to thank the Elsa Pardee foundation (L.Furcht, Allen-Pardee Professor). The authors would like to acknowledge Ali Khammanivong for providing gRNA sequences and guidance during the generation of the CD44 knockout cell lines. The authors would also like to acknowledge the Burroughs Wellcome Fund and the Howard Hughes Medical Institute Medical Research Fellowship program for providing funding for Patrice M. Witschen. 
The authors would like to apologize for these omissions from the original manuscript. These changes do not affect the scientific results.

Conflicts of Interest: The authors declare no conflict of interest.

\section{Reference}

1. Witschen, P.M.; Chaffee, T.S.; Brady, N.J.; Huggins, D.N.; Knutson, T.P.; LaRue, R.S.; Munro, S.A.; Tiegs, L.; McCarthy, J.B.; Nelson, A.C.; et al. Tumor Cell Associated Hyaluronan-CD44 Signaling Promotes Pro-Tumor Inflammation in Breast Cancer. Cancers 2020, 12, 1325. [CrossRef] [PubMed]

(C) 2020 by the authors. Licensee MDPI, Basel, Switzerland. This article is an open access article distributed under the terms and conditions of the Creative Commons Attribution (CC BY) license (http://creativecommons.org/licenses/by/4.0/). 